\title{
Prevalence of Chronic Kidney Disease in Patients with Cardiovascular Disease
}

\author{
Said S. Khamis1, Ahmed M. Zahran1, Nagwa N. Hegazy1, Heba E. Kasem1, Hayam K. El-Fiky2* \\ ${ }^{1}$ Faculty of Medicine, Menoufia University, Al Menoufia, Egypt \\ ${ }^{2}$ Shebin El Kom Teaching Hospital, Al Menoufia, Egypt \\ Email: heba.kasem@yahoo.com, ^hayam.kamal678@gmail.com
}

How to cite this paper: Khamis, S.S., Zahran, A.M., Hegazy, N.N., Kasem, H.E. and El-Fiky, H.K. (2020) Prevalence of Chronic Kidney Disease in Patients with Cardiovascular Disease. Open Journal of Nephrology, 10, 227-240.

https://doi.org/10.4236/ojneph.2020.103022

Received: May 17, 2020

Accepted: July 10, 2020

Published: July 13, 2020

Copyright $\odot 2020$ by author(s) and Scientific Research Publishing Inc. This work is licensed under the Creative Commons Attribution International License (CC BY 4.0).

http://creativecommons.org/licenses/by/4.0/

\section{Open Access}

\begin{abstract}
Background: Chronic kidney disease (CKD) is a worldwide public health alarming problem. Although both heart and kidneys are separated by a quite distance within the body and they perform varied functions, there is a close physiological relationship between them. The diseases in the kidneys can trigger a disease in the heart and vice versa. High blood pressure is the most significant risk factor for the development and progression of chronic kidney disease (CKD). Lowering blood pressure is a goal to prevent CKD progress. Chronic abnormalities in cardiac function (e.g., chronic congestive heart failure) causing, chronic kidney disease and anemia appear to act together in a vicious circle in which each condition causes or exacerbates the other progressive chronic kidney disease. Objective: To assess the prevalence of chronic kidney disease in patients with cardiovascular disease at Shebin El-Kom Teaching Hospital and Menoufia University Hospital Cardiology Outpatient Clinic, Menoufia Governorate, Egypt. Methods: This is a cross-sectional study that was conducted in Shebin El-Kom Teaching Hospital Cardiology Outpatient Clinic, Menoufia University Cardiology Outpatient Clinic from April 2019 to July 2019. This study included 200 patients with cardiovascular disease or hypertension for more than 6 months. All patients were subjected to detailed history taking, clinical examination, laboratory investigation, echo and abdominal ultrasound. Results: This study included 200 patients with cardiovascular disease or hypertension for more than 6 months, which showed that: 63 (31.5\%) were diagnosed as chronic kidney disease, 24 (38\%) known to be CKD, 39 (62\%) not known diagnosed in our study. Uncontrolled hypertension, congestive heart failure, diuretics and ACEI or ARBS with diuretics together are significant risk factors for renal impairment; uncontrolled hypertension and diuretics are the most predictors for renal impairment. Conclusion: Uncontrolled hypertension is the most preventable cause of renal impairment; RAAS not cause renal impairment but lead to de-
\end{abstract}


creased GFR in CKD patients. We should be careful with ACEI or ARBS with diuretics or diuretics only and control congestive heart disease to avoid kidney injury and chronic cardiorenal.

\section{Keywords}

Uncontrolled Hypertension, Congestive Heart Failure, Chronic Kidney Disease, Diuretics, ACEI or ARBS

\section{Introduction}

Chronic kidney disease (CKD) is a global health burden with a high economic cost to health systems and is an independent risk factor for cardiovascular disease (CVD). All stages of CKD are associated with increased risks of cardiovascular morbidity, premature mortality, and/or decreased quality of life [1].

Chronic kidney disease (CKD) is the progressive and irreversible diminishing of kidney function, which leads to the accumulation of both toxins and fluid within the body [2].

Although both heart and kidneys are separated by a quite distance within the body and they perform varied functions, there is a close physiological relationship between them. The diseases in the kidneys can trigger a disease in the heart and vice versa [2] [3].

Hypertension and cardiovascular disease (CVD) are acknowledged to be integrally linked with CKD [3].

There is a graded inverse relationship between CVD risk and glomerular filtration rate (GFR) that is independent of age, sex and other risk factors [1].

Erythropoietin Hormone; secreted by the kidney; is decreased in chronic kidney diseases that leads to decrease in red blood cells production and hence leads to anemia. This anemia can leads to left ventricular hypertrophy with or without anemic heart failure [4].

Congestive heart failure, chronic kidney disease and anemia appear to act together in a vicious circle in which each condition causes or exacerbates the other [5].

Systemic hypertension is transmitted to intra-glomerular capillary pressure leading to glomerulosclerosis and loss of kidney function; thus variable risk of impaired renal function has been reported among hypertensive subjects [6].

Early diagnosis and treatment of the underlying cause and/or the institution of secondary preventive measures are imperative in patients with chronic kidney disease (CKD). These steps may delay, or possibly halt, progression of the disease [5] [6].

We aimed by this study to assess the prevalence of chronic kidney disease in patients with cardiovascular disease at Shebin El-Kom Teaching Hospital and Menoufia University Hospital Cardiology Outpatient Clinic, Menoufia Governorate, Egypt. 


\section{Patient and Methods}

This was a cross-sectional study including 200 patients known to be cardiac included hypertension for more than 6 months at Shebin El-Kom Teaching Hospital Cardiology Outpatient Clinic, Menoufia University cardiology outpatient clinic from April 2019 to July 2019.

Inclusion criteria:

1) Hypertension.

2) Patients with ischemic heart diseases.

3) Patients with congestive heart failure.

4) Patients with rheumatic and valvular heart diseases.

5) Age $>18 \mathrm{yr}$ and $<80 \mathrm{yr}$.

Exclusion criteria:

1) Patients with decompensated chronic liver disease.

2) Patients with terminal malignancy.

3) Age $<18$ yr and $>80 y r$.

4) Diabetic patient.

5) Patient diagnosed as nephrotic syndrome.

6) Patient with psychiatric and mental illness.

Informed consent was obtained from the patients after explaining the research. All study procedures were carried out and approved by the Ethical Committee of Menoufia Faculty of Medicine. Detailed history, Laboratory investigation, Doppler ultrasound and clinical examination was done for all patients with stress on:

1) Medical history of patients known to be hypertension for long time for more than six-month history take ACE or ARBS or and diuretics for more than 6 months, patient diagnosed previously as rheumatic heart disease, congestive heart failure or vulvlar heart disease by echocardiogram for more than 6-month history of diuretic use or ACE or ARBS for more than 6 months. Ask about hypertension controlled on treatment. BP controlled systolic $\mathrm{Bp}<130$ and diastolic Bp $<80$ (American heart association, 2018).

2) Examine pulse.

3) Measure blood pressure to detect if controlled or not Blood pressure was measured by a trained technician using a mercury sphygmomanometer and calculated as the average of 3 or 4 measurements, excluding the first measurement. Adequate blood pressure control was defined SBP $<130 \mathrm{~mm} \mathrm{Hg}$ and DBP $<80$ $\mathrm{mm} \mathrm{Hg}$ for all adults $<65$ years of age and for adults $\geq 65$ years of age with diabetes mellitus. Pulse pressure was calculated as the difference between systolic and diastolic blood pressure; wide pulse pressure was defined as $>80 \mathrm{~mm} \mathrm{Hg}$ [7].

4) Examination of congested neck veins and lower limb for detect patient in congestion in congestive heart failure.

5) Auscultation of first and second heart sound and additional heart sound to detect valvular heart disease.

6) Laboratory investigations include $\mathrm{Hb}(\mathrm{gm} / \mathrm{l})$, Urea $(\mathrm{mg} / \mathrm{dl})$, Creatinine (mg 
/dl), ACR (mg/gm), HbAlc (mmol/mol), Cholesterol (mg/dl)), Triglycerides (mg/dl)), LDL (mg/dl)), HDL (mg/dl)).

We measure urea, creatin and alb/creatin ratio in two occasions three months in between then estimate GFR by EPI CKD equation (chronic kidney disease epidemiology collaboration) [8].

Estimated glomerular filtration rate $(\mathrm{eGFR})\left(\mathrm{ml} / \mathrm{min} / 1.73 \mathrm{~m}^{2}\right)$ calculate by EPI ckd equation (chronic kidney disease epidemiology collaboration):

$(\mathrm{GFR}=141 \times \min (\mathrm{Scr} / \kappa, 1) a \times \max (\mathrm{Scr} / \kappa, 1)-1.209 \times 0.993$ age $\times 1.018$ [if female] $\times 1.159$ [if black], whereas $S c r$ is the serum creatinine value $(\mathrm{mg} / \mathrm{dL}) ; k$ is 0.07 for women and 0.9 for men; $\alpha$ is -0.329 for women and -0.411 for men; $\min$ indicates the minimum of $\mathrm{Scr} / \kappa$ or 1 , and $\max$ indicates the maximum of $\mathrm{Scr} / \boldsymbol{k}$ or 1.10) [8].

We classify CKD patients according to Kidgo 2012 (Table 1) [9].

Based on Estimated glomerular filtration rate all patients will be divided into 2 groups:

- Group I: patients diagnosed CKD (chronic kidney disease).

- Group II: patients diagnosed non CKD (nonchronic kidney disease).

Statistical analysis:

Data were collected and entered into the computer using SPSS (Statistical Package for Social Science) program for statistical analysis, (version 20; Inc., Chicago, IL).

\section{Results}

This study included 200 patients aged from 30 to 80 years ( 80 male and 120 female) the mean age of those patients are $59.5 \pm 9.7$, the mean GFR are $87.03 \pm$ 22.3 , the mean BMI was 323.5, 31.5\% known to be CKD and, $82.5 \%$ known to be hypertensive, $72.5 \%$ known to be IHD, $14 \%$ known to have congestive heart failure, $9 \%$ known to have valvular heart disease, $76.5 \%$ take ACEI/ARBs as treatment, $22 \%$ take diuretics as treatment, $41 \%$ take both ACEI/ARBs and diuretics as treatment as shown in Table 2 we collect patients from cardiology outpatient in Clinic Menoufia University and Shebin El Kom Teaching Hospital exclude diabetic patients as diabetes consider a main predictor for renal impairment worldwide. Compare between all patients regarding labs as shown in Table 3. In our study we divided patients into two groups group 1 patients diagnosed as chronic kidney disease. Group 2 patient diagnosed nonchronic kidney disease according GFR by EPI. We made comparison between two groups regarding demographics as shown in Table 4 we found that congestive heart failure, uncontrolled hypertension, diuretics and diuretics and ACEI or ARBS together are significant risk factors in comparison between two groups as shown in Figure 1 and Table 4.

Prevalence of chronic kidney disease among patients is shown in Figure 2. In our study we detect percent of patients diagnosed previously as CKD which represent as $38 \%$ and patients recently diagnosed which represent $62 \%$ as shown in Figure 3. 
Table 1. Classification of CKD patients according to KIDGO 2012.

\begin{tabular}{ccc}
\hline GFR category GFR $\left(\mathbf{m l} / \mathbf{m i n} / \mathbf{1 . 7 3 m ^ { 2 } )}\right.$ & Terms & \\
\hline G1 & $>90$ & Normal or high $^{\text {G2 }}$ \\
G3A & $60-89$ & Mildly decreased $^{*}$ \\
G3B & $45-59$ & Mildly to moderately decreased $^{2}$ \\
G4 & $30-44$ & Moderately to severely decreased \\
G5 & $15-29$ & Severely decreased \\
\hline
\end{tabular}

Table 2. Patients demographics of all 200 patients.

\begin{tabular}{|c|c|}
\hline Variable & Number (\%) \\
\hline \multicolumn{2}{|l|}{ Gender } \\
\hline Male & $80(40 \%)$ \\
\hline Female & $120(60 \%)$ \\
\hline \multicolumn{2}{|l|}{ CKD } \\
\hline \multicolumn{2}{|r|}{$137(68.5 \%)$} \\
\hline No & \\
\hline \multicolumn{2}{|l|}{ Hypertension } \\
\hline Yes & $165(82.5 \%)$ \\
\hline No & $35(16.5 \%)$ \\
\hline \multicolumn{2}{|l|}{ Hypertension control } \\
\hline Yes & $96(58.2 \%)$ \\
\hline No & $69(41.8 \%)$ \\
\hline \multicolumn{2}{|l|}{ IHD } \\
\hline Yes & $145(72.5 \%)$ \\
\hline No & $55(27.5 \%)$ \\
\hline \multicolumn{2}{|l|}{ Congestive HF } \\
\hline Yes & $28(14 \%)$ \\
\hline No & $172(86 \%)$ \\
\hline \multicolumn{2}{|l|}{ Valvular diseases } \\
\hline Yes & $18(9 \%)$ \\
\hline No & $182(91 \%)$ \\
\hline \multicolumn{2}{|l|}{ ACEI/ARBs } \\
\hline $\begin{array}{l}\text { Yes } \\
\text { No }\end{array}$ & $47(23.5 \%)$ \\
\hline \multicolumn{2}{|l|}{ Diuretics } \\
\hline Yes & $44(22 \%)$ \\
\hline No & $156(78 \%)$ \\
\hline ACEI/ARBs + Diuretics & $41(20.5 \%)$ \\
\hline Yes & $159(79.5 \%)$ \\
\hline No & \\
\hline
\end{tabular}

Table 3. Patients laboratory data of all 200 patients.

\begin{tabular}{cccc}
\hline Variable & Minimum & Maximum & Mean + SD \\
\hline Age (Years) & 30 & 80 & $59.5+9.7$ \\
BMI $\left(\mathrm{Kg} / \mathrm{m}^{2}\right)$ & 23 & 42 & $32+3.5$ \\
$\mathrm{Hb}(\mathrm{gm} / \mathrm{l})$ & 7.0 & 17.0 & $11.7 \pm 1.7$ \\
Urea $(\mathrm{mg} / \mathrm{dl})$ & 10.0 & 160.0 & $39.1 \pm 21.9$ \\
\hline
\end{tabular}




\section{Continued}

\begin{tabular}{cccc}
\hline Creatinine (mg/dL) & 0.40 & 3.0 & $0.96 \pm 0.42$ \\
ACR (mg/gm) & 1.0 & 1000.0 & $131.2 \pm 204.0$ \\
HbAlc (mmol/mol) & 4.5 & 8.0 & $5.4 \pm 0.41$ \\
Cholesterol (mg/dl) & 100.0 & 244.0 & $182.3 \pm 31.4$ \\
Triglycerides (mg/dl) & 55.0 & 215.0 & $99.9 \pm 32.1$ \\
LDL (mg/dl) & 50.0 & 170.0 & $110.1 \pm 24.9$ \\
HDL (mg/dl) & 17.0 & 70.0 & $44.8 \pm 9.4$ \\
eGFR (ml/min/1.73m $\left.{ }^{2}\right)$ & 14.0 & 134.0 & $87.03 \pm 22.3$ \\
\hline
\end{tabular}

BMI: body mass index, HB: hemoglobin, ALB/CR: albumin/creatin, LDL: low density lipoproteins, HDL: high density lipoproteins, GFR: glomerular filtration rate, HB A1C: hemoglobin A1C. -SD: standard deviation.

Table 4. Comparison between studied groups patient diagnosed as chronic kidney disease and patient free from renal impairment regarding demographics.

\begin{tabular}{|c|c|c|c|c|}
\hline Variable & $\begin{array}{c}\text { Group } 1 \\
\text { CKD No (63) }\end{array}$ & $\begin{array}{c}\text { Group 2 } \\
\text { Non-CKD No (137) }\end{array}$ & Test & $P$ value \\
\hline *Age (Years) & $61.3 \pm 11.3$ & $58.6 \pm 8.8$ & 1.8 (t test) & 0.070 (NS) \\
\hline \multicolumn{5}{|l|}{ \#Gender } \\
\hline Male no (\%) & $26(41.3)$ & $54(39.4)$ & \multirow{2}{*}{$0.062(\mathrm{x} 2)$} & \multirow{2}{*}{$0.804(\mathrm{NS})$} \\
\hline Female no (\%) & $37(58.7)$ & $83(60.6)$ & & \\
\hline BMI $\left(\mathrm{kg} / \mathrm{m}^{2}\right)$ & $31.6 \pm 3.9$ & $32.2 \pm 3.4$ & $0.791(\mathrm{U})$ & 0.429 (NS) \\
\hline \multicolumn{5}{|l|}{ Hypertension } \\
\hline Yes no (\%) & $56(88.9)$ & $109(79.6)$ & \multirow{2}{*}{2.6} & \multirow{2}{*}{$0.107(\mathrm{NS})$} \\
\hline No no (\%) & $7(11.1)$ & $28(20.4)$ & & \\
\hline \multicolumn{5}{|c|}{ Hypertension control } \\
\hline Yes no $(\%)$ & $10(17.9)$ & $86(78.9)$ & \multirow{2}{*}{61.2} & \multirow{2}{*}{$0.000(\mathrm{~S})$} \\
\hline No no (\%) & $46(82.1)$ & $23(21.1)$ & & \\
\hline \multicolumn{5}{|l|}{ IHD } \\
\hline Yes no (\%) & $41(65.1)$ & $104(75.9)$ & \multirow{2}{*}{2.5} & \multirow{2}{*}{0.111 (NS) } \\
\hline No no (\%) & $22(34.9)$ & $33(24.1)$ & & \\
\hline \multicolumn{5}{|l|}{ Congestive HF } \\
\hline Yes no (\%) & $14(22.2)$ & $14(10.2)$ & \multirow{2}{*}{5.1} & \multirow{2}{*}{$0.023(\mathrm{~S})$} \\
\hline No no (\%) & $49(77.8)$ & $123(89.8)$ & & \\
\hline \multicolumn{5}{|l|}{ Valvular Disease } \\
\hline Yes no (\%) & $7(11.1)$ & $11(8.0)$ & \multirow{2}{*}{0.500} & \multirow{2}{*}{0.479 (NS) } \\
\hline No no (\%) & $56(88.9)$ & $126(92.0)$ & & \\
\hline \multicolumn{5}{|l|}{ ACEI/ARBs } \\
\hline Yes no (\%) & $48(76.2)$ & $105(76.6)$ & \multirow{2}{*}{0.005} & \multirow{2}{*}{$0.944(\mathrm{NS})$} \\
\hline No no (\%) & $15(23.8)$ & $32(23.4)$ & & \\
\hline \multicolumn{5}{|l|}{ Diuretics } \\
\hline Yes no $(\%)$ & $23(36.5)$ & $21(15.3)$ & \multirow{2}{*}{11.2} & \multirow{2}{*}{$0.001(\mathrm{~S})$} \\
\hline No no (\%) & $40(63.5)$ & $116(84.7)$ & & \\
\hline \multicolumn{5}{|c|}{ ACEI/ARBS + Diuretics } \\
\hline Yes no (\%) & $23(36.5)$ & $18(13.1)$ & \multirow{2}{*}{14.4} & \multirow{2}{*}{$0.001(\mathrm{~S})$} \\
\hline No no (\%) & $40(63.5)$ & $119(86.9)$ & & \\
\hline
\end{tabular}

*: Mean + Standard deviation, \#: Chi square. * BMI: body mass index, IHD: ischemic heart disease, congestive HF: congestive heart failure. ACEI: angiotensin receptor blockers, ARBS: angiotensin converting enzyme inhibitor. 


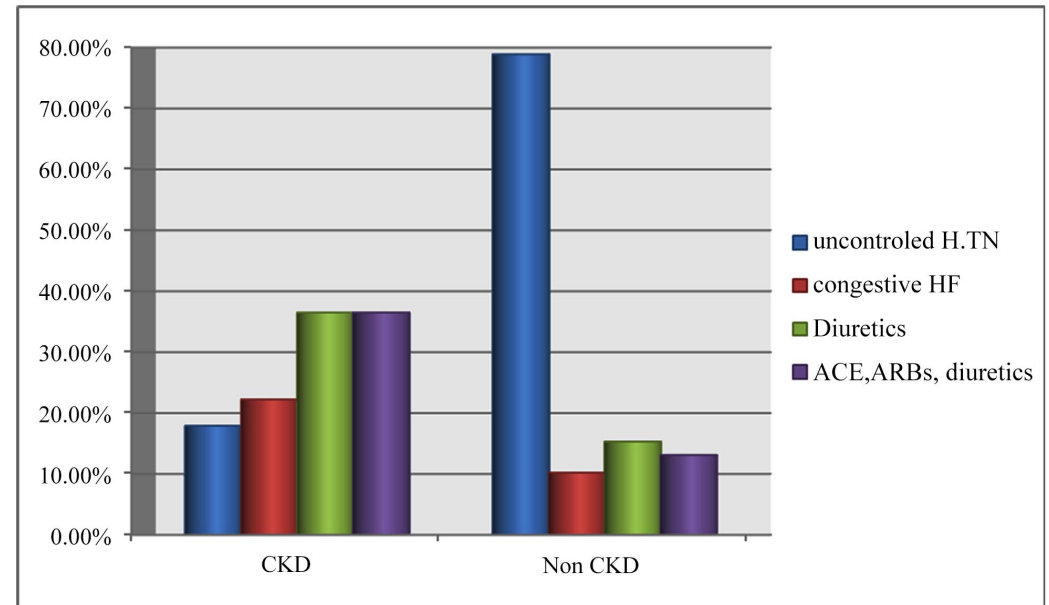

Figure 1. Comparison between CKD and non CKD patients.

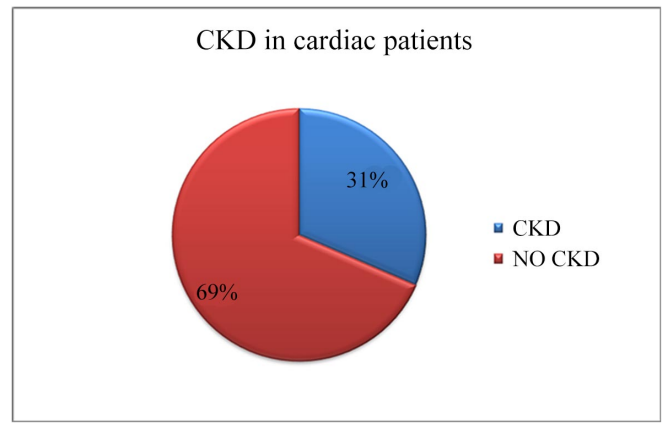

Figure 2. Prevalance of chronic kidney disease.

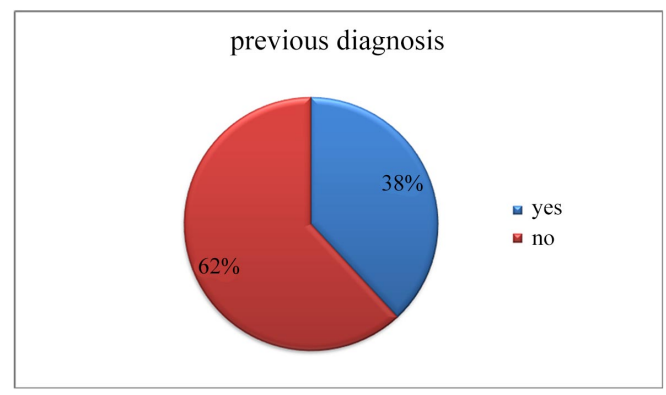

Figure 3. Patients diagnosed having CKD in our study $(n=63)$.

We classify CKD patients according to GRF by EPI equation to 5 stages according to (Kidigo, 2012) as shown in Figure 4 we found that CKD patients in our study were in stage 3 which represent $40.3 \%$ of patient.

We made univariant binary logistic regression analysis to detect the prediction of significant risk factors for renal impairment which shows that diuretics, congestive heart failure, uncontrolled hypertension and diuretics with ACEI or ARBS together as shown in Table 5.

Then we made a multivariant binary logistic regression to detect prediction of risk factors to be significant to renal failure as shown in Table 6 we found that uncontrolled hypertension and diuretics are the more predictor risk factor. 


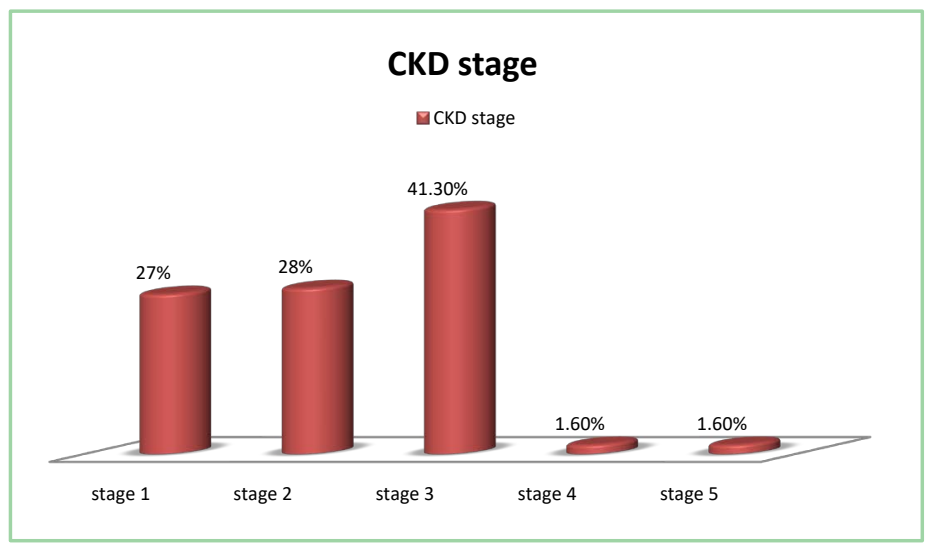

Figure 4. Stages of CKD in cardiac patients $(n=63)$.

Table 5. Univariate binary logistic regression analysis.

\begin{tabular}{ccc}
\hline Variable & \multicolumn{2}{c}{ Univariate binary logistic regression analysis } \\
\hline & Odd $($ CI 95\%) & P value \\
\hline uncontrolled H.TN & $17.2(7.5-32.8)$ & 0.000 \\
Congestive HF & $2.5(1.1-5.7)$ & 0.02 \\
Diuretics & $3.2(1.6-6.3)$ & 0.001 \\
ACEI/ARBs + Diuretics & $3.8(1.9-7.8)$ & 0.000 \\
\hline
\end{tabular}

*Congestive HF Congestive heart failure, ACEI: angiotensin converting enzyme inhibitor, ARBs: amgiotension receptor blocker.

Table 6. Multivariate binary logistic regression analysis.

\begin{tabular}{ccc}
\hline Variable & \multicolumn{2}{c}{ Multivariate binary logistic regression analysis } \\
\hline & Odd (CI 95\%) & P value \\
\hline uncontrolled H.TN & $17.3(7.2-42.1)$ & 0.000 \\
Congestive HF & $2.4(0.56-10.4)$ & 0.237 \\
Diuretics & $5.3(1.4-19.3)$ & 0.010 \\
ACEI/ARBs + Diuretics & $1.9(0.666-5.7)$ & 0.224
\end{tabular}

${ }^{*}$ Congestive HF Congestive heart failure, ACEI: angiotensin converting enzyme inhibitor. ARBs: amgiotension receptor blocker.

\section{Discussion}

Chronic kidney disease (CKD) is a major health care problem due to its associated high morbidity and mortality, increasing prevalence, and elevated costs [10].

A reduction in glomerular filtration rate (GFR) has been related with an increase in the risk of cardiovascular complications and greater morbidity and mortality the high prevalence of CKD is known in patients who either have or are at a high risk of having cardiovascular disease [11].

Impaired renal function independently increases the risk of death, cardiovascular death and hospitalization for worsening heart failure in patients with 
chronic heart failure (CHF) The main determinant of renal function in CHF is renal blood flow [12].

Chronic heart failure (CHF) is common, is an important cause of hospitalizations, and is associated with significant morbidity and mortality. Renal disease in patients with heart failure is multi-factorial. Renal function may act as a barometer of cardiac function [13].

Our study across sectional study was carried out in cardiology outpatient clinic at Shebin El-Kom Teaching Hospital, Menoufia University, Menoufia from April 2019 to July 2019 to assess prevalence of chronic kidney disease in patients with cardiovascular disease.

Two hundred patients were included in this study, $40 \%$ males and $60 \%$ females, with ages ranged from 30 to 80 years old.

All of them were cardiac which were rheumatic or hypertensive or congestive heart disease or all of them for at least 6 months duration we exclude diabetic patient as diabetes main predictor of renal impairment. We divide patients to two groups as follow:

- Group 1-patients diagnosed as CKD according to EPI GFR.

- Group 2-patients not diagnosed CKD according to EPI GFR.

This study aimed to detect prevalence of chronic kidney disease in cardiac patients.

In our study result demonstrated that prevalence of CKD was 63 patient with percent (31\%) of total patient the same study done in Spain Gorostidi et al. [14] unlike our study prevalence of CKD was $15.1 \%$ and same study reported in Brazil by Alves et al. [15] in which prevalence was $36.6 \%$ this similar to our study.

Our result was also similar with a same study reported in Spain by Amenós et al. [11] in which prevalence of CKD was $37.3 \%$.

In our study we divide CKD patient to a group who are known and diagnosed before as CKD which represent $38 \%$ (24 pt) of CKD patient with $12 \%$ of total and another group which screened in our study which represent $62 \%(39 \mathrm{pt})$ of CKD patient around $19.5 \%$ of total population this explain increase the percent of screening in our study and awareness of CKD is low.

Unlike another study reported in Spain by Amenós et al. [11] patient established CRF 18.9\% and patient occult CRF 18.2\% two groups are equal in number our result nearly similar to another study reported in America 29\% were aware of their CKD Murphy et al. [16]

We classify CKD patients according to GRF by EPI equation to 5 stages according to Kidigo (2012) we found that the largest number of CKD patients in our study were in stage 3 which represent $40.3 \%$ of patient and this refers to our patient careless and not aware we also found that stage 1 present $27 \%$, stage 2 present $28 \%$, stage 4 represent $1.6 \%$, stage 5 represent $1.6 \%$, this also found in another study reported in Spain by Gorostidi et al. [14] in which stage 3 represent the largest number $11.6 \%$ stage $1,2,4$ and 5 were $1.8 \%, 1.6 \%, 0.2 \%$ and $0.0 \%$ of subjects.

And also agree with study reported in Brazil by Alves et al. [15] in which stage 
$1(19 \%)$, stage $2(31 \%)$, stage $3(35.8 \%)$, stage $4(9.5 \%)$ and stage $5(4.8 \%)$. also agree with study reported in Spain in which $83.1 \%$ had stage 3; $14.8 \%$ stage 4 ; and $2.1 \%$ stage 5 Amenós et al. [11]. unlike result of study reported in BRAZIL in which stage 3 was $2.3 \%$ although this study show different population than we collect and also disagree with study reported in America compare between American African regarding controlled hypertension 25\% had stage 1, 35\% had stage 2, 33\% had stage 3, and 6\% had stage 4 CKD Murphy et al. [16].

In our study we compare between two groups regarding some demographics and risk factor to detect the most risk factor for renal impairment.

Our result demonstrated no significant difference between two groups regarding hypertension, age, gender, BMI, IHDS and vulvlar heart disease.

BMI ranges in our study from 23 to 41 with mean $32 \pm 3.5$. We found no significant difference between two groups regarding BMI and this similar to Amenós, et al. [11] in which BMI did not differ widely between two groups but chronic renal failure affects more the obese patient.

We found no significant difference between two groups regarding age but CKD affected the older more than this agree with Gorostidi et al. [14] Individuals with CKD were older than subjects with normal renal parameters (61.5 vs. 44.4 years), and were predominantly and agree with Amenós et al. [11] in which no significant difference regarding age but CRF more in old patient.

In our study we found no significant difference regarding gender but female affected more than male affected with $58.7 \%$ and male $41.3 \%$ this agree with Amenós et al. [11] male affected with 25\% and disagree with Gorostidi et al. [14] in which male affected more than 3 -fold higher in men than in women $(23.1 \%$ vs. $7.3 \%)$, men affected with (75.4\%).

Our result demonstrated that Number of patient of vulvlar heart disease around $9 \%$ of total population and ischemic heart disease represent around $72.5 \%$ of total population prevalence of CKD in vulvlar and IHDS was $11.1 \%$ and $65.1 \%$ of $\mathrm{CKD}$ we found no significant difference between two groups regarding IHDS and vulvlar heart disease this agree with Song et al. [17] in which no significant difference regarding renal function frequent occurs in elderly regarding vulvlar heart disease and profoundly affect long-term outcomes.

Our result demonstrated hypertensive patients around 165 patients with percent 82.5 our result disagree with study reported in Spain by Gorostidi et al. [14].

In our study hypertension represent around $37 \%$ of total population prevalence of CKD in hypertension patient was $28 \%$ of all subject and with $88.5 \%$ percent of $\mathrm{CKD}$ patients this explains that hypertension the major cause of CKD this disagree with Alves et al. [15] a same study in al brazil in which prevalence of CKD in hypertensive patient was $17.3 \%$.

Our result demonstrated that hypertension is the most effective cause of renal impairment but there is no significant difference between two groups regarding hypertension as hypertension patient around $78.9 \%$ of non CKD patients agree with study reported in Spain by Amenós, et al. [11] in which hypertension in CKD patient was $91.8 \%$ and $78.7 \%$ of non CKD patients there was no significant 
difference between two groups.

In our study we found that uncontrolled hypertension the most effective risk for renal impairment patient with CKD and uncontrolled hypertension around $82.1 \%$ of all CKD patient and control hypertension is important preventable cause for renal impairment as $17.9 \%$ of controlled get CKD and $78.9 \%$ of non CKD patient this similar to study reported in America by Murphy et al. [16] in which percent of $\mathrm{CKD}$ in uncontrolled hypertension around 73\%. Also agree with another study reported in Saudi Arabia by Almalki et al. [18] in which uncontrolled hypertension $78.1 \%$ and associated with more comorbidity like renal impairment.

Our result demonstrated that ischemic heart disease 145 patient with percent $72.5 \%$ of total patient, congestive heart failure 28 with percent $14 \%$ of total patient and vulvlar heart disease 18 with percent $9 \%$ of total patient prevalence of CKD in with $65.1 \%$ in IHDS, and $22.2 \%$ in congestive HF and $11.1 \%$ in vulvlar diseases disagree with study reported in Spain Gorostidi et al. [14] cardiovascular disease represent about $2.2 \%$ of all population with prevalence of CKD around $15.1 \%$ in CVD disagree with another study reported in United States by George et al. [19] in which prevalence of CKD in HF was $28.3 \%$ and $22 \%$ the percent of decline in GFR and there is a significant difference regarding H.F like our study prevalence of CKD in non-congestive HF was $1.6 \%$ this explain that uncontrolled congestive heart failure is often associated with a rapid fall in renal function and adequate control of congestive heart failure can prevent progress of renal impairment.

Also our study demonstrated significant difference between two groups regarding uncontrolled hypertension, congestive heart failure, diuretics and ACEI/ARBS + diuretics.

Our result demonstrated that prevalence of CKD with history of diuretics were 44 patient with percent of $22 \%$ of total patient disagree with study reported in Al Brazil by Alves et al. [16] in which percent of diuretic use 78\%. Our result demonstrated that prevalence of CKD with diuretics around $36.5 \%$ of CKD patients and around $11.5 \%$ of all patients. there is a significant difference between two groups regarding diuretic use this agrees with a study reported in Europe by De Silva et al. [20] compare between diuretic use for more than 6 months in H.F regarding kidney dysfunction in this study prevalence of kidney dysfunction in group taking diuretics around 63\% increase risk of kidney dysfunction with $50 \%$ and there was a significant difference regarding diuretic use.

In current study 153 patient take ACEI or ARBS with percent $76.5 \%$ this agree with percent of study in brazil by Alves et al. [16] in which, 67\% take ACEI and $4.5 \%$ receiving $\mathrm{ARBs}$ our result demonstrated prevalence of $\mathrm{CKD}$ with ACEI or ARBS was $76.2 \%$ of $C K D$ patient and $24 \%$ of total patient, we found there was no significant difference between two groups regarding history of having ACEI or ARBS agree with study reported in America by McCallum et al. [21] in which GFR reduced in a group talking ACE or ARBS statistically increased risk for kidney dysfunction, the risk is limited to the early phase there was no significant 
difference between two groups regarding talking ACEI or ARBS prevalence of CKD in ARBS use around 33\% prevalence of group take placebo around with no significant difference regarding ACEI or ARBS taking.

Our result demonstrated significant difference between two groups regarding decrease parenchyma, decrease length and increase echogenicity this agree with study reported in India by Maneesha et al. [22] they found that length decrease and parenchyma last affected in the last stage of CKD and correlate with increase creatinine.

In our result univariant binary logistic regression analysis demonstrated that the more predictive risk factor for renal impairment were uncontrolled hypertension [odds ratio (95\% CI), 17.2 (7.5 - 32.8), $\mathrm{p}<0.000$ ], congestive heart failure [odds ratio (95\% CI), 2.5 (1.1 - 5.7), $\mathrm{p}<0.02$ ], Diuretics [odds ratio (95\% CI), 3.2 (1.6 - 6.3), $\mathrm{p}<0.001$ ] and ACEI/ARBs + Diuretics [odds (95\%), 3.8 (1.9 $7.8), \mathrm{p}<0.000]$.

We made multivariant binary logistic analysis which demonstrated that the most predictive risk factors for renal impairment were uncontrolled hypertension [odds (95\% CI), 17.3 (7.2 - 42.1), p < 0.000] agree with Murphy et al. [16] also agree with Wright et al. [23] in which uncontrolled hypertension was the most risk factor for renal impairment and another predictive risk factor for renal impairment is diuretics [odds (95\% CI), 5.3 (1.4 - 19.3), $\mathrm{p}<0.010$ ] agree with Alves et al. [14] and disagree with Clark et al. [24].

\section{Limitation}

The study was conducted over a short period and included only 2 centers which may not represent all patients in Menoufia Governorate.

\section{Conclusion}

Uncontrolled hypertension, diuretics, ACEI OR ARBS together with diuretic and congestive heart failure are the significant risk factors for renal impairment in cardiac patients.

\section{Conflicts of Interest}

The authors declare no conflicts of interest regarding the publication of this paper.

\section{References}

[1] Hill, N.R., Fatoba, S.T., Oke, J.L., et al. (2016) Global Prevalence of Chronic Kidney Disease-A Systematic Review and Meta-Analysis. PLoS ONE, 11, e0158765. https://doi.org/10.1371/journal.pone.0158765

[2] Webster, A.C., Nagler, E.V., Morton, R.L., et al. (2017) Chronic Kidney Disease. The Lancet, 389, 1238-1252. https://doi.org/10.1016/S0140-6736(16)32064-5

[3] Luyckx, V.A., Tuttle, K.R., Garcia-Garcia, G., et al. (2017) Reducing Major Risk Factors for Chronic Kidney Disease. Kidney International Supplements, 7, 71-87. https://doi.org/10.1016/j.kisu.2017.07.003 
[4] Ryu, S.R., Park, S.K., Jung, J.Y., et al. (2017) The Prevalence and Management of Anemia in Chronic Kidney Disease Patients: Result from the Korean Cohort Study for Outcomes in Patients with Chronic Kidney Disease (KNOW-CKD). Journal of Korean Medical Science, 32, 249-256. https://doi.org/10.3346/jkms.2017.32.2.249

[5] Khilji, F.U.R., Iqbal, Q., Haider, S., et al. (2019) Frequency, Prognosis and Risk Factors of Congestive Heart Failure in Dialysis Patients Attending Public Hospitals in Pakistan. Advances in Medical, Dental and Health Sciences, 2, 3-18. https://doi.org/10.5530/amdhs.2019.1.4

[6] Lea, J.P. and Nicholas, S.B. (2002) Diabetes Mellitus and Hypertension (2002): Key Risk Factors for Kidney Disease. Journal of the National Medical Association, 94, 7-15.

[7] Carey, R.M., Calhoun, D.A., Bakris, G.L., et al. (2018) Resistant Hypertension: Detection, Evaluation, and Management: A Scientific Statement from the American Heart Association. Hypertension, 72, 53-90.

[8] Stevens, L.A., Levey, A.S., Schmid, C.H., et al. (2009) A New Equation to Estimate Glomerular Filtration Rate. Annals of Internal Medicine, 150, 604-612. https://doi.org/10.7326/0003-4819-150-9-200905050-00006

[9] Kidney Disease Improving Global Outcomes (KDIGO) (2012) Clinical Practice Guideline for the Evaluation and Management of Chronic Kidney Disease. Kidney International Supplements, 3, 19-62.

[10] Wang, V., Vilme, H., Maciejewski, M.L., et al. (2016) The Economic Burden of Chronic Kidney Disease and End-Stage Renal Disease. Seminars in Nephrology, 36, 319-330. https://doi.org/10.1016/j.semnephrol.2016.05.008

[11] Amenós, A.C., González-Juanatey, J.R., Gutiérrez, P.C., et al. (2010) Prevalence of Chronic Kidney Disease in Patients with or at a High Risk of Cardiovascular Disease. Revista Espanola de Cardiologia (English Edition), 63, 225-228. https://doi.org/10.1016/S1885-5857(10)70041-4

[12] Damman, K., Kjekshus, J., Wikstrand, J., et al. (2016) Loop Diuretics, Renal Function and Clinical Outcome in Patients with Heart Failure and Reduced Ejection Fraction. European Journal of Heart Failure, 18, 328-336. https://doi.org/10.1002/ejhf.462

[13] Gray, R.M., Newton-John, T., Lee, J., et al. (2017) Intimate Relationships and Chronic Illness: A Literature Review for Counsellors and Couple Therapists. Psychotherapy and Counselling Journal of Australia, 5, 1-12.

[14] Gorostidi, M., Sánchez-Martínez, M., Ruilope, L. M., et al. (2018) Chronic Kidney Disease in Spain: Prevalence and Impact of Accumulation of Cardiovascular Risk Factors. Nefrología (English Edition), 38, 606-615.

https://doi.org/10.1016/j.nefroe.2018.04.010

[15] Alves, L.F., Abreu, T.T.D., Neves, N.C.S., et al. (2017) Prevalence of Chronic Kidney Disease in a City of Southeast Brazil. Brazilian Journal of Nephrology, 39, 126-134. https://doi.org/10.5935/0101-2800.20170030

[16] Murphy, K.A., Greer, R.C., Roter, D.L., et al. (2020) Awareness and Discussions about Chronic Kidney Disease among African-Americans with Chronic Kidney Disease and Hypertension: A Mixed Methods Study. Journal of General Internal Medicine, 35, 298-306. https://doi.org/10.1007/s11606-019-05540-3

[17] Song, F., Liu, F.Z., Liang, Y.F., et al. (2019) Clinical, Sonographic Characteristics and Long-Term Prognosis of Valvular Heart Disease in Elderly Patients. Journal of Geriatric Cardiology: JGC, 16, 33.

[18] Almalki, Z.S., Albassam, A.A., Alhejji, N.S., et al. (2020) Prevalence, Risk Factors, 
and Management of Uncontrolled Hypertension among Patients with Diabetes: A Hospital-Based Cross-Sectional Study. Primary Care Diabetes. https://doi.org/10.1016/j.pcd.2020.02.004

[19] George, L.K., Koshy, S.K., Molnar, M.Z., et al. (2017) Heart Failure Increases the Risk of Adverse Renal Outcomes in Patients with Normal Kidney Function. Circulation: Heart Failure, 10, 1-8. https://doi.org/10.1161/CIRCHEARTFAILURE.116.003825

[20] De Silva, R., Nikitin, N.P., Witte, K.K., et al. (2006) Incidence of Renal Dysfunction over 6 Months in Patients with Chronic Heart Failure Due to Left Ventricular Systolic Dysfunction: Contributing Factors and Relationship to Prognosis. European Heart Journal, 27, 569-581. https://doi.org/10.1093/eurheartj/ehi696

[21] McCallum, W., Tighiouart, H., Ku, E., et al. (2020) Trends in Kidney Function Outcomes Following RAAS Inhibition in Patients with Heart Failure with Reduced Ejection Fraction. American Journal of Kidney Diseases, 75, 21-29. https://doi.org/10.1053/j.ajkd.2019.05.010

[22] Maneesha, K., Raju, Y.G.S. and Kumar, J.S. (2020) A Comparison between Renal Cortical Thickness and Renal Size as an Indicator of Renal Function in Chronic Kidney Disease Cases, in Tertiary Care Centre, King George Hospital, Visakhapatnam, Ap, India. Indian Journal of Applied Research, 10, 20-23.

[23] Wright, J.T., Bakris, G., Greene, T., et al. (2003) African American Study of Kidney Disease and Hypertension: Effect of Blood Pressure Lowering and Antihypertensive Drug Class on Progression of Hypertensive Kidney Disease: Results from the AASK Trial. The Journal of the American Medical Association, 288, 2421-2431. https://doi.org/10.1001/jama.288.19.2421

[24] Clark, A.L., Kalra, P.R., Petrie, M.C., et al. (2019) Change in Renal Function Associated with Drug Treatment in Heart Failure: National Guidance. Heart, 105, 904-910. 